\title{
IS ANYBODY KEEPING THE CODE IN BULGARIA? A STUDY TO EXPLORE LOCAL PARENTS' AWARENESS REGARDING THE INTERNATIONAL CODE FOR THE MARKETING OF BREAST-MILK SUBSTITUTES.
}

\author{
Ivanichka Serbezova $^{1}$, Daniela Lyutakova ${ }^{2}$
}

\begin{abstract}
:
This paper reviews Bulgarian parents' awareness concerning the existence of the WHO Code for the marketing of breast-milk substitutes and how it can help them optimize their breastfeeding journey. Frequently occurring problems and breaches of the Code in Bulgaria are discussed, and their context explained. We focus on parental attitudes and investigate whether they acknowledge the significant necessity for a Code-compliant prenatal education and postnatal care. We also explore their viewpoints on the implementation of the Code and maximizing compliance with it on a local level. The research findings are presented graphically, and we present tendencies showcased by respondents' opinions they have expressed in the survey.

OBJECTIVES: Purposes of this research are: (1) to explore parents' awareness about the WHO Code and their encounter with local prenatal classes in this regard (2) to assess their viewpoints on implementing the Code and if they see it as a significant step towards an optimal breastfeeding experience.

METHODS: The methods we applied include an online-based cross-sectional semi-quantitative questionnaire with closedended and open-ended questions, aiming to explore parents' current knowledge and viewpoints in regard to the Code and its implementation in Bulgaria. The research has been carried out via social media, and it samples parents from a local parent peer support group. Acquired data from closed-ended questions is presented, demonstrating percentages and tendencies.

RESULTS: A total of 463 respondents are included

CONCLUSION: It is a common practice in Bulgaria for prenatal classes not to comply with the WHO Code. Disregarding recommendations and evidence-based medicine, both some experts and companies under the scope of the Code breach its main points. Code-compliant prenatal education is practically almost non-existent with the lack of midwife-led care and classes, predominantly in the private sector, where they are almost entirely, sponsored by those companies. Nearly all parents included in this survey are more than willing and motivated to have access to Code-compliant prenatal education and postnatal care. The lack of such leaves almost no choice for Bulgarian parents actually to have access to code-compliant education and care. This inevitably influences their decision making, attitudes and behavior, potentially leading to lower breastfeeding rates and suboptimal breastfeeding satisfaction and success. Adequate measures must be reinforced to ensure implementation and proper legislation, providing monitoring and enforcement, protecting parents and their babies when they are most vulnerable.
\end{abstract}

UDC Classification: 618, DOI: https://doi.org/10.12955/pmp.v2.188

Keywords: breastfeeding, lactation, formula, healthcare, midwife, breast-milk

\section{Introduction}

The importance of breastfeeding and its benefits has been broadly investigated and well documented as modern science has given us insight into how a biological norm can be so intricate and complex, yet wondrously simple, in providing survival and thriving for children and families. It is only logical for humankind to aspire to protect and safeguard this integral part of being a highly evolved mammal with whatever measures necessary. As of 1981, the World Health Organization developed the International Code of Marketing of Breast-milk Substitutes (International Code or hereafter - the Code), also providing regular updates that have been adopted since. The International Code aims to ensure safe and adequate provision of nutrition for infants by protecting and promoting breastfeeding through a set of measures and provision of adequate information WHO (2016). It also directs the safe use and distribution of breast-milk substitutes when they are needed, and informed and ethical marketing. All these recommendations are key to achieving optimal rates of breastfed infants, thus minimizing health risks and optimizing health outcomes for children everywhere, including Bulgaria, where topics as children mortality and morbidity are still a great challenge. As per Black (2008), globally, infants who are not exclusively breastfed are 14 times more likely to die than exclusively breastfed infants.

\section{Literature Review}

As Tulleken (2020) marks, also citing de Preneuf (2020), lockdown measures have diminished household income, and the UN World Food Programme estimates that by the end of 2020, 265 million people may be facing food insecurity, making breastfeeding even more important. Although Bulgaria is part of the EU, the country still faces many adversities in providing adequate maternity and child care.

\footnotetext{
${ }^{1}$ Ruse University „Angel Kanchev“, Faculty of Public Health and Health Care, iserbezova@uni-ruse.bg, ORCID: (https://orcid.org/0000-0002-1195-2512), Ruse, Bulgaria

${ }^{2}$ Ruse University „Angel Kanchev“, Faculty of Public Health and Health Care, lyutakova.daniela@gmail.com, Ruse, Bulgaria
} 
This is demonstrated by the sky-high rate of c-sections, at 43.1 percent, Bulgaria has the third-highest percentage of Caesarean births among European Union countries, as Eurostat data shows (Eurostat, 2021); and the lack of early initiation of breastfeeding as per Bagci Bosi (2016); short duration of exclusive breastfeeding Petrova, S. (2010). These are among the many red flags in regard to poor health outcomes for mothers and babies here. Maternal and infant mortality rates are also alarming. Eurostat data also showed in 2018, the highest infant mortality rates in the EU, where the average rate is 3.4 for both 2018 and 2019, were registered in Romania - 6.0 deaths per 1000 live births, and Bulgaria with 5.8 deaths. Again, in 2019, Bulgaria still held a place in the top three with 5.6 deaths per 1000 live births as per Eurostat. All of this compelling data points us to look at the measures in place which are supposed to enhance breastfeeding, as a key factor for infant and maternal health, and regulations on breast-milk substitutes (hereafter BMS).

According to the World Health Organization's Status Report (2020), in Bulgaria, some provisions of the Code have been included in the country's legal frame. On the other hand, it becomes clear that Bulgaria actually does not identify who is responsible for monitoring compliance, does not define "sanctions for violations, and doesn't require that monitoring and enforcement should be independent, transparent and free from commercial influence" as per the same document. Furthermore, data demonstrated in this report shows our total score for all categories, regarding compliance with the Code, is 39 out of 100 , and we are not only lacking any monitoring and enforcement, but we also score 0 points in both categories - promotion in health care facilities and engagement with health workers and systems.

In light of these circumstances, we searched for any relevant and up-to-date information regarding protective measures for breastfeeding in Bulgaria. The latest record we found was from 2006. Then, the Bulgarian group of The World Alliance for Breastfeeding Action (WABA) held an event for World Breastfeeding Week (WBW). This meeting presented results from independent research among 210 mothers in 7 cities and 76 spots distributing infant food. Their data indicated:

- $12 \%$ of mothers, who have decided to formula feed, were convinced to do so by medical experts as early as in the maternity ward.

- $18 \%$ of all surveyed parents have received different promotional materials, associated with the promotion of BMS and products under the scope in maternity wards.

- $14 \%$ of mothers were convinced to incorporate a specific BMS product by their general practitioners and pediatricians, who happen to be distributors of this said brand of BMS

- $42 \%$ of these respondents are highly educated, and only $3.5 \%$ of them have breastfed their infants until the age of 6 months and beyond.

- $15 \%$ of enquired mothers are confident in the importance of breastfeeding up to 1 year and beyond, and the research finds this percentage consists predominantly of Islamic women

- 76 distribution spots were included in the research, and in all 76 of them, promotional materials prompting parents to formula feed were found.

Later on, in 2012, the same group conducted another research, "Inspection on Possibilities for Social Control over the Policies for Infant Feeding and Health in Times of Crisis". It consisted of 680 respondents in 12 cities - mothers and medical experts.

- $82 \%$ of all respondents state they have lived through a natural disaster but had no access to organized, protected points for breastfeeding mothers and their children;

- $100 \%$ of the respondents of medical background confirmed that measures required by the Code were not taken into consideration in those critical times;

- $72.5 \%$ of surveyed mothers said that the focus is mainly on breastfeeding promotion, but not so much on control and real support through the competent NGOs, social networks, employers, law provisions, and effectiveness and guaranteed working healthcare system.

All this comes as an evidence that keeping the Code in Bulgaria is somewhat an illusion. This prompts us to investigate more recent information and explore parents' attitudes and awareness regarding the matter - hence the current research. Thus, the current research aims to paint a clearer picture of parental awareness and attitudes towards the Code and also look into common breaches and how they are perceived by Bulgarian parents, whether they are willing to recognize such unethical marketing as a direct threat, a threat that needs to be eliminated. 


\section{Data and Methodology}

This research was carried out in the time frame of the 5th of March 2021 until the 15th of March 2021, via a cross-sectional study design and data collection using a self-administered online questionnaire, consisting of only closed-ended questions. This was targeted at parents, predominantly mothers, members of an online community for peer support, mainly breastfeeding.

Within the first segment of this survey, we have tried to locate social-media groups, using the Facebook search with keywords and phrases: "mothers", "lactation", "breastfed baby", "breastfeeding". The target participants in our research were women with membership in online support groups for parents in Bulgaria, particularly mothers. The survey we have employed was based on a self-selected sample and was computer-assisted. It was posted as an accessible link in a closed Facebook group after a group administrator's approval. Notably, not all administrators, whom we contacted, regarding our study, approved of the questionnaire being published in the groups we have selected. We will explore this further in the discussion. The participation method for this research was random, and respondents were reached exclusively via the Facebook platform.

This online questionnaire was constructed specifically for the current, it included 9-point questionnaire, developed via Google Forms, using checkbox type of questions. Those questions were presented to all respondents in the exact same order, and an answer to all 9 of them was required.

With the first 2 questions, we try to explore the demographic data of respondents, while with the second one - we look at respondents' awareness and experiences regarding the Code and Code compliant or non-compliant services. Participants were provided with participant information in the publication, containing the access link and the content of the questionnaire was briefly described. A short note was included at the end of the survey with an accessible link with further details.

Respondents have filled out the survey voluntarily and anonymously online, and a total of 463 respondents are included in this study. The response rate is $54.59 \%$. In the interpretation, we used the quantitative analysis method. Both authors reviewed the responses and organized data from closed-end questions in Microsoft Excel Version 2016. Further, data was analyzed within Excel, and descriptive statistics were produced.

\section{Survey Results}

We have presented graphically collected data and organized it in tables and figures to allow for a clearer interpretation of observed tendencies. The results are divided into two segments as follows.

\section{Demographic Data}

To warrant some context for latter data, we have tried to outline some main characteristics of the respondents we have included in our survey in this first segment. Of course, it is of significant importance if parents we have reached have any experience with breastfeeding and to what extent they have meddled in the topic's hot points.

\begin{tabular}{|l|c|c|c|c|c|c|c|c|c|c|}
\hline \multicolumn{2}{|l|}{ Table 3: Demographic Data of Respondents } \\
\hline Indicator & Cat. 1 & $\mathbf{\%}$ & Cat. 2 & $\mathbf{\%}$ & Cat. 3 & \% & Cat. 4 & \% & Cat. 5 & \% \\
\hline $\begin{array}{l}\text { Age } \\
\text { profile }\end{array}$ & $\begin{array}{c}18-20 \text { years } \\
\text { old }\end{array}$ & 0.9 & $\begin{array}{c}21-25 \text { years } \\
\text { old }\end{array}$ & 13.4 & $\begin{array}{c}26-34 \text { years } \\
\text { old }\end{array}$ & 58.3 & $\begin{array}{c}35-40 \\
\text { years } \\
\text { old }\end{array}$ & $\begin{array}{c}22.9 \\
\begin{array}{c}41-50 \\
\text { years } \\
\text { old and } \\
\text { over 50 }\end{array}\end{array}$ \\
\hline $\begin{array}{l}\text { Parity \& } \\
\text { Gravidy }\end{array}$ & $\begin{array}{c}\text { Nulliparous/ } \\
\text { primigravida }\end{array}$ & 1.7 & primiparous & 58.3 & multiparous & 39.7 & N/A & 0.2 & - & - \\
\hline
\end{tabular}

Our findings indicate the majority of surveyed parents have at least one child - a total of $98 \%$. This is unsurprisingly in sync with what we know to be the profile of the Facebook group we have surveyed in. It is only logical peer support for breastfeeding is predominantly sought after by women who already have children.

\section{Parental Experience and Attitudes}

The second segment of our survey explores mothers' awareness and experience in regard to keeping the Code. And so, our first question has the objective of establishing how familiar respondents are with the Code. We have asked them if they are informed about the Code, its existence, and what it entails. 


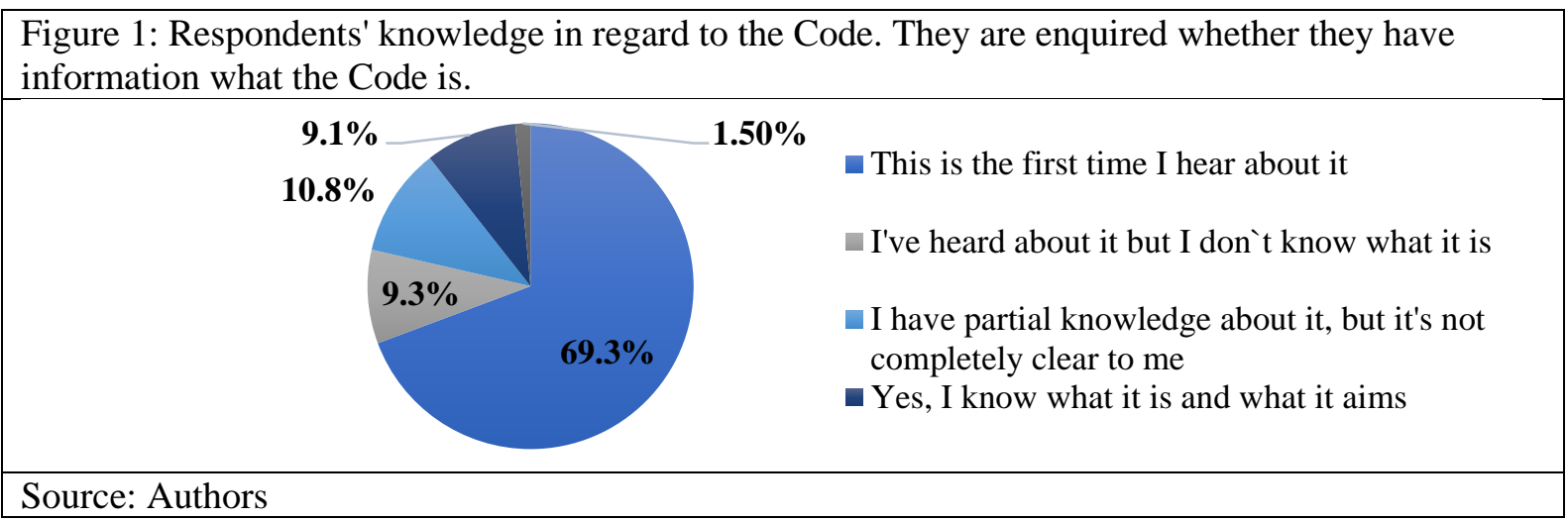

This data shows that most women state they are unaware of the Code and what measures are included in it. A considerable amount of surveyed parents $-69.3 \%$ or 321 respondents, state they had no preexisting knowledge on the matter at the time of the survey.

These findings have to be considered while examining all further data from the current study, as having no context influences respondents' answers and limits their ability to express realistic viewpoints regarding the topic. This observation is most valid while examining respondents' impressions on keeping the Code. It is hard to discern their experiences and get a clearer picture of the real circumstances when parents are not exactly sure what the Code even is.

\begin{tabular}{|l} 
Figure 2: Respondents' viewpoints on keeping the Code. Respondents are enquired whether they \\
think the Code is being complied with locally. \\
\hline $\mathbf{6 . 0 \%}$ \\
$\mathbf{7 3 . 7 0 \%}$
\end{tabular}

Source: Authors

Numbers clearly demonstrate lack of information about the Code which logically leads to parents not being able to discriminate thoroughly between compliant and non-compliant services.

The next point of our research is decidedly the one that gives us clearest viewpoints on how parents perceive breastfeeding support importance and the Code's place within the complex of maternity and child care. We have asked respondents to express their readiness to reject services on the grounds of brands breaching the Code. Enquired whether they would opt out of any parental education events sponsored by brands under the scope of the Code, respondents have stated the following opinions:

Figure 3: Respondents' attitudes towards non-compliant parental education and healthcare. They are asked if they are willing to reject such services on the ground of the Code measures.

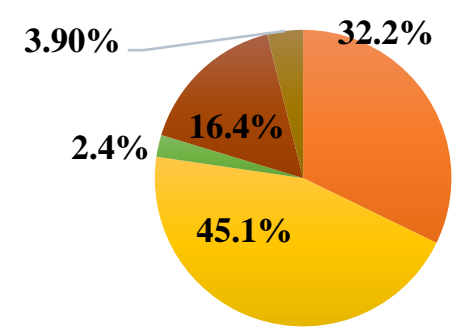

No, there is no reason for me to reject

No, but I'll have the breach in mind

No, things are connected, it is even a

bounus if those brands are sponsors

Yes, I would not use such services

Source: Authors

A considerable percentage of enquired parents, $32.2 \%$, state they don't see any reasoning behind rejecting non-compliant services. Markedly, only $16.4 \%$ are ready to abandon any plans on partaking in 
such parental classes. Another $45.1 \%$, almost half of the respondents, think they can attend such events, provided they have this non-compliant sponsorship in mind.

In the next figure, parents share their own experience with examples of this breach.

Figure 4: Respondents' experience with non-compliant parental education and care: have they received promotional materials, samples, and gifts from brands under the scope of the Code during any kind of parental education events.

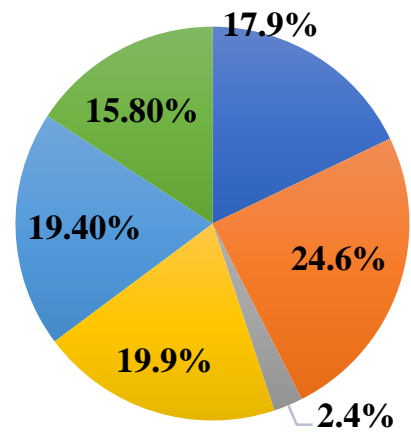

Yes, I have been given promotional materials,

samples and gifts from those brands

Yes, I have received one of the above

mentioned

No, but they gave those to others in attending

I haven't received any personally, but I kow it to be a common practice

I haven't received any personally, there is no such practice

This question doesn't apply to me

Source: Authors

A total of $44.9 \%$ of the respondents state they personally or other attending parents have received one or more of the aforementioned objects while attending parental education events - any promotional materials (leaflets, stickers, booklets, key chains, pens, measure tapes, t-shirts, carrying the brand logo, etc.), samples (samples of formula), gifts (predominantly feeding bottles and accessories, pacifiers, breastfeeding pumps from brands who also distribute bottles and/or formula). Another $19.9 \%$ point to their knowledge of this breach but somehow have avoided being offered or receiving those gifts. This makes up for $64.8 \%$ of all included respondents.

So far, we mostly look at expectant parents' experiences. The next question asks about their perceived view on support for breastfeeding in vulnerable times of difficulties. It is a general question, not identifying the source of recommendations.

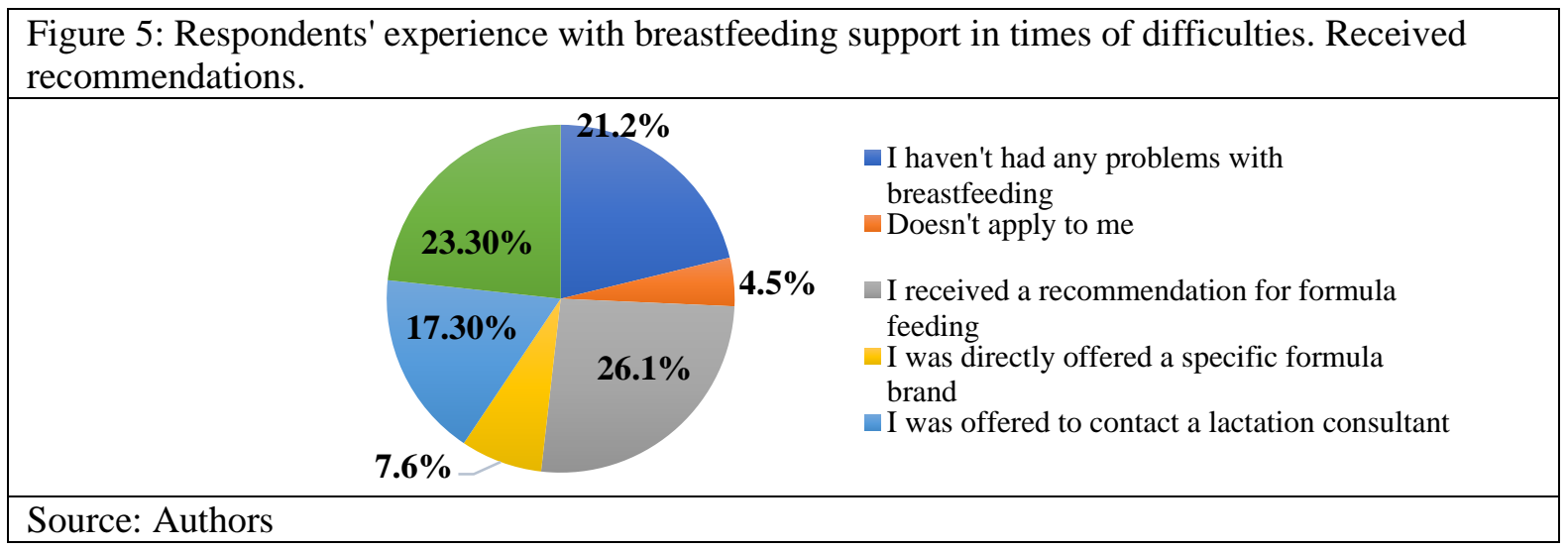

It is of significant importance to underline that this current survey has been posted in a group specifically aimed at peer support for breastfeeding mothers and consists of both mothers with positive experience in breastfeeding and peer supporters, who have some informal training in lactation consulting form nonprofit NGOs. Thus, results have to be interpreted considering they are not a true representation for the whole Bulgarian population of breastfeeding and postpartum women, as only a small number of them are members of the group. This, to a great extent, explains why a total of $40.6 \%$ of respondents have been directed toward a lactation consultant or specific measures for overcoming their breastfeeding problems. Still, a considerable percentage of enquired mothers $-33.7 \%$ have been directly offered formula feeding, with $7.6 \%$ receiving a recommendation for a specific formula brand.

In light of this data, it is vital to explore parental attitudes towards stricter and clearer policies in regard to implementing the Code. 


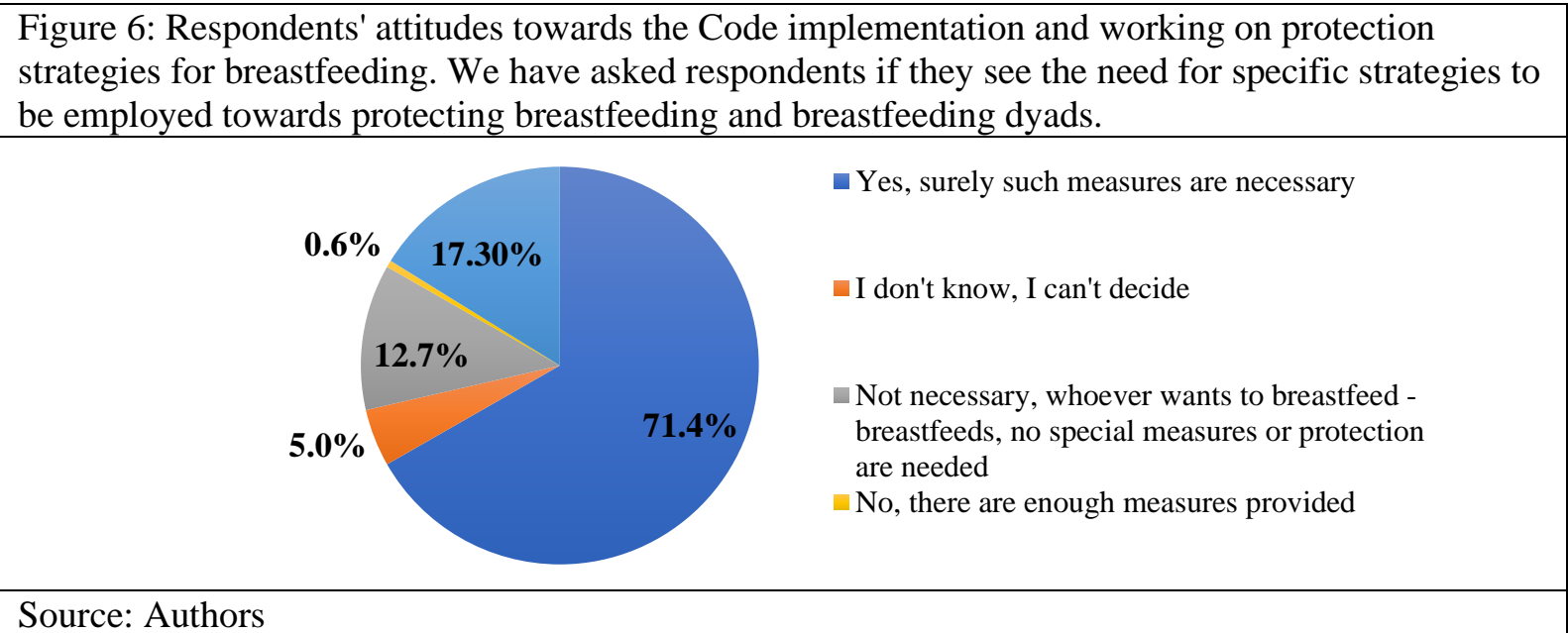

Notably, a total of $88.7 \%$ are adamant measures protecting breastfeeding are a must, with $17.30 \%$ of those pointing to the Code being legislated as a necessary step in the right direction.

Figure 7: Respondents' attitudes towards the Code implementation and working on protection strategies for breastfeeding. We have asked respondents if they think there are any local effectively working measures protecting breastfeeding in reality.

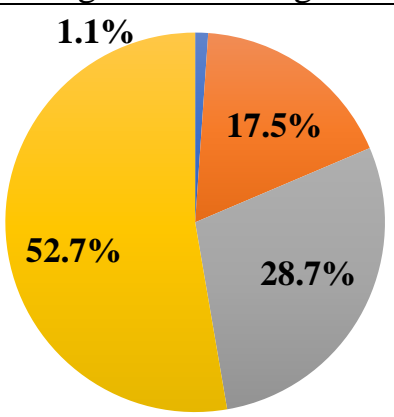

$$
\begin{aligned}
& \text { Yes, there are measures for breastfeeding } \\
& \text { mothers at work } \\
& \text { Yes, the law ensures some measures, but they } \\
& \text { are not effectively enforced and parents are } \\
& \text { not informed about them enough } \\
& \text { No measures are ensured, we are left to our } \\
& \text { own devices } \\
& \text { I don't kow of any such measures }
\end{aligned}
$$

\section{Source: Authors}

It is evident lack of awareness, and accessible information are a key point in our situation - with a bit over half of the respondents stating that they don't know of any such measures. Taking into consideration that this survey has been conducted with a highly motivated and experienced group of parents, who have a demonstrated interest in breastfeeding and its protection, it is even more so worrisome.

\section{Discussion}

During such unprecedented times, facing a pandemic and unparalleled isolation has notably been really hard on mothers with infants, as Brown (2020) reminds us, it is of great significance to turn our eyes to vulnerable people. Breastfeeding as a strategy for survival is not something new to the world, yet we somehow manage to forget it. Tulleken (2020) underlines that by contrast with the need for supporting breastfeeding at times of the coronavirus march, large manufacturers of BMS have inappropriately positioned themselves as sources of public health expertise and suggested various unnecessary hygiene measures, the use of expressed breast-milk, and the separation of mothers from their babies. Clearly, such recommendations undermine breastfeeding and thus increase the risk of infant death as overwhelming evidence shows us. Having no consistent information on ethical practices in regard to BMS marketing and proper breastfeeding support and education could be definitely considered a risk factor for breastfeeding struggles and vulnerability among Bulgarian women, as the surveyed group showed a combined percentage of 89.4 don't have a clear knowledge and understanding of the Code. As most parental classes in Bulgaria, if not all, transformed into online events over the last year, anecdotal data on Code non-compliant practices has been overwhelming. Currently, prenatal care locally is dominated almost entirely carried out by Obstetricians, and midwife-led care is almost nonexistent. This leaves little to no time for proper preparation and education on how to care for the baby, and this vacuum is filled by various parental classes, sponsored predominantly by brands under the scope of the 
Code. This breach is not surprising, having in mind there are no monitoring and enforcement procedures in place and parents themselves don't know what to look out for. With $73.7 \%$ sharing they can't say if they have seen any breaches since they have no idea what the Code states it is pressing we find ways to raise awareness on the matter effectively. Looking at data about parents' willingness to partake in different events breaching the Code, sponsored by brands under its scope, is even more concerning. Almost half of the respondents, $45.1 \%$ of our participants, are under the impression they can probably somehow neutralize conflicting recommendations and information that such parental classes give out. This is extremely telling about the current situation and points us to the markedly low awareness of the risks that undermining breastfeeding poses to new parents and their babies. The fact that some of the respondents, even if a small number $(2.4 \%)$, consider it a bonus to have such brands sponsor such events, as things are connected in their opinion, also poses a problem. Nearly half of the surveyed mothers, or $44.9 \%$, say they personally or other attending parents have received promotional products and/or gifts and samples, breaching the Code. Another $19.9 \%$ gave anecdotal data that makes them believe this is a common practice here. This is totaling $64.8 \%$ of all respondents, even though the examined group has predominantly consisted of mothers highly motivated to breastfeed and such that have a positive experience with breastfeeding. Also, a considerable percentage of enquired mothers $-33.7 \%$ have been directly offered formula feeding when they experienced difficulties with breastfeeding; another $7.6 \%$ of them received a recommendation for a specific brand of formula. Bulgarian mothers often get conflicting advice from medical experts in maternity wards, pediatrician consultations, and through online sources and support groups, as practices of giving newborns water with glucose and tea, enforcing "night pauses", etc. are still observed locally. The good news is respondents recognize the need for wellstructured support and protection that helps them optimize their breastfeeding experience. It is vital any and every institution and organization working in this field makes the effort to work together and install an effective and working algorithm of monitoring and enforcing the Code.

\section{Challenges and Limitations}

The survey was conducted in a specific online peer support group focused on breastfeeding mothers. This evidently puts some limitations on our results, as the surveyed sample cannot be considered representative for all Bulgarian women. Also, a broader group of respondents, including such contacted for interviews should be considered for a follow-up research, as to gain even more reliable data. It is really necessary for profound national monitoring to be conducted to get a clearer view of what actually happens and what circumstances Bulgarian mothers navigate. Another point we have to make is the difficulties we encountered when distributing the survey. Notably, some of the group administrators we have reached declined to publish the survey. Further investigation showed the group administrator promotes BMS and other products under the scope of the Code in said groups.

\section{Conclusion}

As evidenced by this and earlier surveys, Bulgaria hasn't escaped the ruthless lobbying and unethical practices of the big brands under the scope of the International Code. We can also conclude that uninformed parents are a big percent, which is logically instrumental to the success of breaching the Code locally. A reliable research looking at parents' experiences and viewpoints has to be conducted nationally to assess all weak points and problems we have to deal with (change is rejected as "has" refers to "a reliable research" which is singular). This has to be undertaken by the responsible organs of the government, as a resistance born from financial interests is evident. It is clear that strong measures have to be taken to provide monitoring that is independent, transparent, and free from commercial influence. Although some legislative measures have been undertaken, without adequate and working instruments for monitoring and enforcement, they are destined to failure, failing parents and children, too. Late events, regarding the COVID-19 pandemic have outlined even more clearly pressing matters in maternity care in Bulgaria and in the world, leaving those who are most vulnerable isolated and even more vulnerable. It is only fair, responsible professionals and organizations lead the way to a safer future.

\section{References}

Bagci Bosi, A. T., Eriksen, K. G., Sobko, T., Wijnhoven, T. M., \& Breda, J. (2016). Breastfeeding practices and policies in WHO European Region Member States. Public health nutrition, 19(4), 753-764.

https://doi.org/10.1017/S1368980015001767 
Black, R. E., Allen, L., Bhutta, Z., et al. (2008). Maternal and child undernutrition: global and regional exposures and health consequences, PlumX Metrics, doi: https://doi.org/10.1016/S0140-6736(07)61690-0

Brown, A., Shenker, N., (2020). Experiences of breastfeeding during COVID-19: Lessons for future practical and emotional support, doi: https://doi.org/10.1111/mcn.13088

Bulgarian group of WABA (2012). Rezultati ot monitoring na tema: "Proverka na văzmožnostite za socialen kontrol na politikite za detsko hranene i zdrave v uslovijata na kriza." [Monitoring survey titled "Inspection on Possibilities for Social Control over the Policies for Infant Feeding and Health in Times of Crisis"]. Results retrieved March 12, 2021 from https://news.bg/bulgaria/karmeneto-u-nas-ne-e-zashtiteno-alarmirat-eksperti.html

Bulgarian group of WABA. (2006). Zaključenie ot godišnata srešta na Globalen alians za zaštita na detskoto hranene i zdrave po slučaj SSK, [Conclusion of their annual meeting on the occasion of WBW], Retrieved March 11, 2021 from http://www.bebe.bg/Svetovna_sedmitsa/zakliuchenie.htm

de Preneuf F, (2020), Food security and COVID-19. Retrieved March 10, 2021 from -

https://www.worldbank.org/en/topic/agriculture/brief/food-security-and-covid-19

Eurostat, (2021), Infant mortality rates. Retrieved March 10, 2021 from - https://tinyurl.com/3hv4pmvf

Petrova S, Rangelova L, Duleva V et al. (2010) Current children's breastfeeding practice in Bulgaria and determinants. Bulg J Public Health 4, 11-26. Retrieved March 11, 2021 from - http://ncpha.government.bg/files/Jurnal_NCPHP_4_2010.pdf

Tulleken, C., Wright, C., Brown, A., et al. (2020). Marketing of breastmilk substitutes during the COVID-19 pandemic, doi: https://doi.org/10.1016/S0140-6736(20)32119-X

World Food Programme, (2020). Risk of hunger pandemic as coronavirus set to almost double acute hunger by the end of 2020. Retrieved March 10, 2021 from - https://insight.wfp.org/covid-19-will-almost-double-people-in-acute-hunger-by-endof-2020-59df0c4a8072

World Health Organization International Code of Marketing of Breast-Milk Substitutes and Subsequent Resolutions. [(accessed on 10 March 2021)]; Retrieved March 10, 2021 from: https://www.who.int/nutrition/netcode/resolutions/en/

World Health Organization (2020). Marketing of Breast-milk Substitutes: National Implementation of the International Code | Status Report 2020. Retrieved March 10, 2021 from https://resourcecentre.savethechildren.net/node/17628/pdf/9789240006010-eng.pdf

World Health Organization (2017). The International Code of Marketing of Breast-milk Substitutes. Frequently Asked Questions. 2017 Update. Retrieved March 10, 2021 from -

https://resourcecentre.savethechildren.net/node/18972/pdf/the_international_code_of_marketing_of_breast-

milk_substitutes_-_frequently_asked_questions.pdf 